\title{
VALORES METATEXTUALES DE CIOĖ EN EL MARCO DE LA GRAMÁTICA CONTRASTIVA ITALIANO/ESPAÑOL: DE LA REFORMULACIÓN A LA CONEXIÓN DEDUCTIVA
}

\author{
Carmen Solsona Martínez \\ Universidad de Zaragoza
}

\begin{abstract}
Resumen: El presente trabajo aborda el estatuto lingüístico de cioè, considerado, esencialmente, un adverbio conjuntivo. Se analiza su valor léxico y la proyección que alcanza en la construcción del discurso. Se presta especial atención a sus funciones metatextuales (siempre en contraste con el español): reformulador objetivo, reformulador subjetivo y conector deductivo. Se aportan, en conclusión, desde un enfoque contrastivo, las implicaciones de dicho abanico de funciones en la enseñanza del italiano/L2.
\end{abstract}

Palabras clave: Marcador discursivo, cioè, italiano L2, funciones metatextuales, reformulación discursiva.

Abstract: This paper addresses the linguistic status of the italian reformulation marker cioè, considered essentially a conjunctive adverb. We analyse its lexical value and the projection that reaches in the construction of discourse. We pay special attention to their metatextual functions (always in contrast with Spanish): objective reformulation marker, subjective reformulator marker and deductive connector. We provide finally, from a contrastive approach, the implications of this range of functions in teaching Italian as a second language. Key words: Discourse marker, cioè, Italian SL, metatextual functions, discoursive reformulation

\section{INTRODUCCIÓN}

La investigación sobre los marcadores del discurso o segnali discorsivi goza de muy buena salud. Los enfoques desde los que se aborda su estudio y análisis son muy variados: categoría y propiedades gramaticales, funciones discursivas, clasificación, traducción, enfoque contrastivo, etc. La bibliografía es muy rica, tanto en el campo de la lengua italiana, como en el de la lengua española (más abundante esta última). En el caso de los marcadores discursivos analizados desde un punto de vista didáctico (italiano/L2) o desde la doble perspectiva (italiano / español) son bastantes los autores que se han ocupado de ellos: Lenarduzzi (1995), Calvo (2001), Flores Acuña (2003a y b, 2007, 2009), 
Fernández Loya (2004), Calvi y Mapelli (2004), Barbero Bernal y Flores Acuña (2006), Muñoz Medrano (2005), Sáinz González (2003, 2006), Vázquez Pérez (2008), Solsona (2011), Bazzanella y Borreguero (2011), Flores Requejo (2012a y b), por citar solo a algunos. Pues bien, este es el marco en el que se inscribe nuestra aportación, en la que nos ocupamos de la partícula italiana cioè, una palabra funcional del italiano que, al igual que otras como por ejemplo ma, allora, insomma o dunque, posee una amplia gama de funciones y usos. Presenta, como todas ellas también, un índice de frecuencia muy alto en la lengua (escrita y oral) de hablantes nativos de italiano. Sin embargo, la interlengua de aprendices hispanohablantes de italiano/L2 muestra un nulo empleo de cioè en los primeros niveles y un uso escaso en los niveles intermedio y superior, lo que hace que sea un elemento muy interesante para ser analizado en el marco de la enseñanza del italiano a hispanohablantes.

Comenzaremos con una presentación de la partícula cioè, mostrando sus características lingüísticas esenciales y su tratamiento en los principales diccionarios monolingües italianos y bilingües italiano-español para pasar, a continuación, a exponer los valores discursivos de cioè. En este trabajo, nos ocuparemos de la función reformulativa del marcador (perteneciente a la macrofunción metatextual), es decir, cuando el hablante se hace presente en el enunciado a través de cioè incidiendo en lo que se dice, bien con la intención de explicar, matizar, explicitar, ejemplificar, reconsiderar, corregir, valorar una formulación previa, bien para llegar a una conclusión, expresar una consecuencia, subrayar un punto de la información, todo ello de lo formulado previamente.

Como decimos, nuestra exposición se centrará en uno de los valores que puede desempeñar cioè dentro de la macrofunción metatextual, el valor como reformulador, sin pretender abordar el resto de los valores de esta partícula, tampoco en las otras dos macrofunciones (metacomunicativa y cognitiva) ${ }^{1}$, si bien, como veremos, en algunas ocasiones los valores no son puros y podremos encontrar casos en los que cioè introduzca reformulaciones y participe, al mismo tiempo, de valores metacomunicativos y/o cognitivos.

Dentro del valor reformulativo de cioè analizaremos características distribucionales, semánticas y lógicas del signo. ¿Cuáles son las posiciones o la colocación sintáctica que presenta? ¿Quién -de los participantes en el acto comunicativo- puede llevar a cabo la reformulación que marca cioè? ¿Qué relación establece este signo entre los miembros que conecta? ¿Son objetivas o son subjetivas las reformulaciones expresadas por cioè?, etc.

Todos los ejemplos que presentamos son ejemplos reales, procedentes de textos escritos de distintos géneros (periodísticos, literarios, científicos, técnicos,

${ }^{1}$ Seguimos la clasificación de López Serena y Borreguero Zuloaga (2010), que retomaba la de Bazzanella (2005), cuando esta autora añadió un tercer grupo -las funciones cognitivas- a su clasificación anterior: interactivas y metatextuales $(1995,2001)$, al igual que hicimos en Solsona (en prensa) al ocuparnos del marcador italiano insomma. 
publicitarios, etc.) y de textos orales (películas, entrevistas televisivas, etc.), así como de textos escritos que reflejan la lengua hablada (tomados de chats y foros de internet), acompañados de la correspondiente traducción al español2.

\section{ESTATUTO LINGÜÍSTICO DEL MARCADOR DISCURSIVO ITALIANO CIOÈ}

\subsection{Cioè como signo complejo}

En cuanto a su estructura morfológica, cioè es un elemento compuesto (al igual que ossia, difatti, infatti, insomma), formado por el pronombre neutro 'ciò' y la tercera persona del presente de indicativo del verbo essere 'è', y se trata de un calco de la forma latina $i d$ est (id=ciò y est=è). Como señalan los diccionarios etimológicos consultados, Cortelazzo y Zolli (1999: 342), Battisti y Alessio (1975: 950), la forma separada ciò è y la forma unida cioè convivieron hasta al menos el siglo XVI y, hasta entonces también, la forma cio è coexistía con las formas ciò sono, ciò era, es decir, los dos elementos eran relativamente autónomos. El verbo essere podía aparecer en variedad de tiempos verbales (ciofû, ciò era, cio è) y con variedad de número en la $3^{\mathrm{a}}$ persona, singular o plural (ciò è, ciò sono). A partir del siglo XVI cioè se lexicaliza y aparece como forma única.

El significado nuclear de cioè es el de aclaración y procede de su etimología ('esto' [lo que acabamos de decir] 'es' [explicación]). En todos los diccionarios monolingües y bilingües consultados, como veremos más adelante, el valor declarativo-explicativo es el primero que se recoge. No obstante, nuestro marcador puede desempeñar distintas funciones, reconducibles en su mayoría a este valor principal declarativo-explicativo, identificables exclusivamente en el seno del texto en el que aparece, debido principalmente a la fuerte incidencia del contexto en la interpretación de estos elementos.

Asimismo, la partícula cioè ofrece dificultades de catalogación, pues es considerada, según las gramáticas y los diccionarios que se tomen como referencia, bien una conjunción, bien un adverbio. Algunas características de este signo, como su libertad distribucional, nos pueden llevar a pensar que se comporta más bien como un adverbio, y otras, como su capacidad de enlazar miembros con diversos valores significativos, nos llevaría a considerarla más bien una conjunción.

En las gramáticas, Serianni (1988: 458) señala que cioè es la conjunción coordinada explicativa por excelencia; Dardano y Trifone (1989: 400) también la catalogan como conjunción coordinante explicativa o declarativa, al igual que Sensini (1997: 390); Fogarasi (1969/1984: 330), como conjunción declarativa

${ }^{2}$ He indicado al final de cada ejemplo, entre paréntesis, el lugar preciso de donde este se ha tomado remitiendo a la Bibliografía Textual (BT, es decir, los textos consultados) con un número que identifica el texto aludido para evitar citas excesivamente largas. En la traducción al español, figura en cursiva la traducción referida a cioè; se verá que, en algunos casos, ha sido necesario recurrir a estrategias de traducción como la compensación, la inversión, la transposición o la amplificación. 
o demostrativa; Carrera (1984/1992: 184), como conjunción declarativa. Por otro lado, Lonzi (en Renzi y Salvi 1991: 388 y 412) la cataloga como adverbio expositivo o textual; Scorretti (en Renzi 1988: 231), como operador de coordinación adverbial, y Sensini (1997: 355-6), como adverbio declarativo o explicativo ${ }^{3}$. Ferrari y Zampese (2000: 275) vendrían a aunar posiciones, ya que la consideran conector -conettivo-, una categoría que engloba distintos tipos de palabras desde un punto de vista sintáctico: conjunciones coordinantes, conjunciones subordinantes, preposiciones, locuciones preposicionales y adverbios o conjunciones que no son ni subordinantes ni coordinantes (el caso de cioè y otros como infatti, insomma, tuttavia, comunque, per esempio, dunque, di conseguenza, allora).

Este último punto de vista viene a reconocer la existencia de la clase funcional de los conectores discursivos (segnali discorsivi) que, como se sabe, engloba unidades invariables que, perteneciendo a distintas clases de palabras (conjunciones y locuciones conjuntivas; adverbios y locuciones adverbiales, conjuntivos, etc. $-\mathrm{cf}$. Greenbaum (1969)-), coinciden en la función conectora de enlazar o relacionar, de acuerdo con sus propiedades morfológicas, sintácticas y semánticas, dos o más fragmentos del discurso y, en general, sobre todo, de orientar las inferencias que se producen en este (Martín Zorraquino y Portolés Lázaro 1999: 4057). Por ello, la NGLE de la RAE y ASALE (2009: 2287) distingue una clase transversal (los marcadores o conectores discursivos) que engloba a los elementos aludidos. En la lingüística italiana, deben destacarse especialmente sobre el tema las contribuciones de Bazzanella (1995), por supuesto, pero también las de Berretta (1984), que ya señaló entre los connettivi testuali a las interjecciones (eh), conjunciones coordinantes (e, ma) y subordinantes (perché justificativo), adverbios (cioè, intanto, appunto), y añadía "ma si tenga conto dei confini incerti di queste categorie, nelle grammatiche come nei vocaboli" (1984: 243). En efecto, como subraya Berretta, es difícil determinar la clase de palabra a la que pertenece cioè. Véase, sin embargo, lo que indicamos al final del presente subapartado.

Los principales diccionarios clasifican esta partícula principalmente como adverbio, tanto los monolingües4: Battisti y Alessio, Cortelazzo y Zolli -los diccionarios etimológicos consultados-, Battaglia, Zingarelli, A. Gabrielli, G. Gabrielli, Devoto e Oli, Palazzi y Pittàno, Treccani, como los bilingües:

${ }^{3}$ Sensini reconoce que esta forma, como otras, oscila entre el valor de conjunción y el de adverbio; como conjunción cuando predomina la función de unir proposiciones y, como adverbio, cuando la función que prevalece es la de determinar una palabra. Por esto, presenta cioè como conjunción en la página 390 y habla de cioè como adverbio declarativo o explicativo en las páginas 355-6, dentro de un grupo de adverbios calificados por él como avverbi fuori serie, al igual que insomma, dunque o ecco.

${ }^{4}$ Los diccionarios que mencionamos a continuación son muy conocidos. Las referencias bibliográficas completas se incluyen en la Bibliografía, al final del presente trabajo. 
Martínez Amador, Carbonell, Ambruzzi, Lavacchi y Nicolás, Espasa Paravia, Calvo y Giordano, aunque también los hay que la consideran conjunción (dos monolingües: el GRADIT de De Mauro y el Sabatini Coletti -este segundo la etiqueta como conjunción textual- y uno bilingüe: Sañé y Schepisi); el diccionario bilingüe Tam considera adverbio a la partícula cioè cuando se utiliza independientemente en construcción interrogativa y, conjunción, en los valores explicativo y correctivo.

La clase de palabra a la que pertenece cioè (signo claramente lexicalizado) resulta difícil de determinar. Su carácter tónico, con todo, nos permite indicar, de momento, que se trata de un adverbio conjuntivo. Su función es de dimensión esencialmente pragmática $\mathrm{y}$, por tanto, para interpretarlo correctamente, tendremos siempre que acudir al contexto (lingüístico y extralingüístico).

Como veremos en los numerosos ejemplos que presentamos y en las diferentes traducciones de este signo en español, el hecho de considerarlo un signo complejo se debe principalmente a que, aunque su valor principal sea el de reformulador -dentro de las funciones metatextuales-, no siempre se comporta como un simple reformulador, sino que posee también valores que -partiendo de la reformulación- van más allá y, de funciones puramente metatextuales de tipo reformulativo, pasamos, a través de la reformulación subjetiva, a funciones cognitivas, comportándose en estos casos como un puro marcador consecutivo. Pasemos, a continuación, a analizar las distintas características de nuestro marcador, lo que nos permitirá acercanos mejor a conocer qué tipo de palabra es cioè.

\subsection{Propiedades distribucionales o sintácticas de cioè}

¿Qué clase de palabra es cioè? Se trata de un signo lexicalizado que se ha gramaticalizado: ha dejado de funcionar como una frase verbal [ciò è] para convertirse en un marcador discursivo, en principio de tipo reformulativo. Sin embargo, cabe plantearse, a tenor de su comportamiento sintáctico y distribucional, qué tipo de palabra es cioè, pues dentro de los reformuladores existen distintos tipos de signos: adverbios, conectores, frases verbales, etc. Veamos detalladamente sus propiedades distribucionales o sintácticas, de las que ya hemos adelantado algunos rasgos característicos.

\subsubsection{Colocación}

Cioè puede ocupar posiciones relativamente libres dentro de la frase con valor reformulador, como muestran los siguientes ejemplos (y como es característico de un adverbio conjuntivo: cf. Greenbaum 1969): 
- Posición inicial

1. cioè vuoi sapere cosa pensava sant'agostino della Bibbia?5 (BT1)

'Cioè / O sea, ¿quieres saber qué pensaba San Agustín de la Biblia?'

- Posición intermedia

2. «Umu», cioè «giorno». In assiro-babilonese. L'Università di Chicago completa il dizionario dopo 90 anni di lavoro. (BT2)

"UUmu», cioè les decir, «día». En asiriobabilónico. La Universidad de Chicago termina el diccionario tras 90 años de trabajo.'

- Posición final

3. grazie fiabo. ti leggo solo ora. vivendo fra il po, l'alaska e l'irlanda faccio quello che posso, sempre poco cioè. un bacione. (BT3)

'gracias fiabo. Ahora mismo acabo de leer tu mensaje. viviendo entre el po, alaska e irlanda hago lo que puedo, poco, cioè / la verdad. un besote.'

Con valor reformulativo, no obstante, lo más frecuente es encontrar el marcador entre el término o segmento de referencia y la correspondiente aclaración, explicación o corrección, es decir, en posición intermedia, semejante a la colocación en español de 'es decir', 'o sea'. No obstante, cuando el marcador se halla en posición intermedia, es interesante observar la gama de colocaciones de cioè en italiano, mucho mayor que la de 'es decir' u 'o sea', como se ve en los siguientes ejemplos (entre el verbo auxiliar y el participio, ej. 4; entre el verbo copulativo y su atributo, ej. 5; entre el demostrativo y el relativo, ej. 6; entre el verbo modal y el infinitivo, ej. 7; entre el verbo y el suplemento, ej. 8), lo que puede ser una causa de la dificultad para comprender el marcador en la L2 e incluso para emplearlo.

4. La sconfitta di Acireale ci ha fatto riflettere. Abbiamo cioè capito che talvolta non basta giocar bene, serve anche un pizzico di fortuna. (BT4)

'La derrota de Acireale nos ha hecho reflexionar. Hemos cioè / es decir

${ }^{5}$ Esta posición al comienzo de frase es frecuente en las heterorreformulaciones, en las que el interlocutor inicia su intervención con un cioè que introduce una formulación que retoma la del hablante con el objetivo, en la mayoría de los casos, de solicitar una confirmación al hablante de que ha entendido correctamente lo que este ha dicho.

${ }^{6}$ Dada la polifuncionalidad intrínseca de los marcadores discursivos, no suele producirse una identificación completa en los valores (significados y sentidos) que expresan cuando se contrastan unidades afines de lenguas diferentes. Por ello, cioè viene a coincidir con los reformuladores españoles 'o sea', 'es decir', pero no podemos identificarlo plenamente con un solo reformulador español (el hecho es aplicable a muchos otros tipos de palabras que no son marcadores del discurso). En las traducciones que proponemos para los ejemplos que analizamos, mantenemos, por ello, el signo original en italiano, al tiempo que proporcionamos, en cada caso, el equivalente más adecuado para el español. 
- pues entendido que quizá no basta con jugar bien, sino que hace falta también un poco de suerte. ${ }^{7}$ [Hemos entendido, pues, que quizá...]

5. È evidente: a volere lo «sviluppo» in tal senso è chi produce; sono cioè gli industriali. (BT5)

'Está claro: quien quiere el «desarrollo» en ese sentido es quien produce, son cioè / es decir - pues los empresarios.' [...quien produce, es decir, los empresarios]

6. L'offerta è nata da una trattativa sbrigativa, quasi da mercato, e sembra fatta apposta per approfittare dei soggetti più deboli, quelli, cioè, che hanno perso tutto, soldi, vestiti, valigie ed anche la speranza di una bella vacanza. (BT6)

'La oferta surgió de una negociación apresurada, casi mercantil, y parece hecha a posta para aprovecharse de los individuos más débiles, aquellos, cioè / es decir - pues, que lo han perdido todo, dinero, ropa, maletas e incluso la esperanza de unas bonitas vacaciones.' [...los individuos más débiles, es decir, aquellos que lo han perdido todo]

7. L'asilo nido deve essere in grado di garantire una accoglienza plurale, deve cioè sapere accogliere e mettere insieme bambini diversi che si trovano a svolgere insieme delle attività (giocare insieme, imparare, ecc.). (BT7)

'La escuela infantil tiene que ser capaz de garantizar una acogida plural, tiene que cioè / es decir saber acoger y coordinar a niños diferentes que tienen que desarrollar juntos distintas actividades (jugar, aprender, etc.).' [...tiene que ser capaz de garantizar una acogida plural, es decir, tiene que saber acoger y coordinar...]

8. I dati parlano chiaro: quasi 5,6 milioni di italiani si trovano in condizione di divario digitale, difettano cioè delle nozioni di base per poter usufruire dei benefici del web. (BT8)

'Los datos hablan por sí solos: casi 5,6 millones de italianos se hallan en situación de brecha digital, carecen cioè / es decir de las nociones básicas necesarias para poder beneficiarse de las ventajas de la red.' [...en situación de brecha digital, es decir, carecen de las nociones básicas...]

La colocación de cioè transmite, como lo hace también su entonación, información de tipo pragmático. En el ej. 3, tomado de un chat de internet, nuestro marcador aparece al final, tras la explicación sempre poco del segmento al que hace referencia [faccio] quello che posso. El hecho de colocarlo al final añade a la explicación el matiz de resignación y cierto descontento, y contribuye, además, a hacer más explícita una relación lógica de causa-consecuencia-que

7 El lector observará que la traducción propuesta en español para los ejemplos del italiano trata de ser bastante literal, con objeto de que se perciban las características lingüísticas del marcador estudiado al trasvasarlo al español. Tras cada ejemplo, entre corchetes, se ofrece la correspondiente traducción propuesta simple y, al final de todos los ejemplos, una traducción más apropiada desde el punto de vista estilístico. 
lleva implícita también la solicitud de disculpa-y que el destinatario -gracias al cioè- puede reconstruir más fácilmente: "Puesto que vivo entre el Po, Alaska e Irlanda, hago lo que puedo, más bien poco, la verdad y, por esto, te escribo ahora que acabo de leer tu mensaje [con cierto retraso, se entiende]".

3. grazie fiabo. ti leggo solo ora. vivendo fra il po, l'alaska e l'irlanda faccio quello che posso, sempre poco cioè. un bacione.

'gracias fiabo. leo ahora tu mensaje. viviendo entre el po, alaska e irlanda hago lo que puedo, poco, cioè / la verdad. un besote.'

En el ej. 4, se destaca en la reformulación (por la especial colocación de cioè) que lo más importante es que se ha 'entendido' algo. El hecho de no poder colocar en español un signo reformulador aclarativo como 'es decir' donde lo ha puesto el emisor italiano nos hace buscar estrategias compensatorias en nuestra traducción para destacar precisamente lo que el hablante ha querido enfatizar, de suerte que, más allá de la traducción literal que hemos propuesto, podríamos aportar también otra, más adecuada estilísticamente, que ofrecemos a continuación:

4. bis La sconfitta di Acireale ci ha fatto riflettere. Abbiamo cioè capito che talvolta non basta giocar bene, serve anche un pizzico di fortuna.

'La derrota de Acireale nos ha hecho reflexionar. Y lo más importante es que hemos entendido que quizá no basta con jugar bien, sino que hace falta también un poco de suerte.'

En el caso de cioè, frente a lo que no puede hacerse con 'es decir' u 'o sea' en español, el hablante coloca el marcador justo delante de lo que considera más significativo en la reformulación, como se ve en el ej. 6, en el que también la posición entre comas del marcador con su correspondiente pausa contribuyen a este valor de focalizador (podría haberlo colocado antes del demostrativo quelli, pero 'los que lo han perdido todo' no tendría la misma fuerza). Como hemos indicado para el caso anterior, ofrecemos, de nuevo, una traducción más adecuada estilísticamente:

6 bis. Lofferta è nata da una trattativa sbrigativa, quasi da mercato, e sembra fatta apposta per approfittare dei soggetti più deboli, quelli, cioè, che hanno perso tutto, soldi, vestiti, valigie ed anche la speranza di una bella vacanza.

'La oferta surgió de una negociación apresurada, casi mercantil, y parece hecha a posta para aprovecharse de los individuos más débiles, aquellos, en definitiva, que lo han perdido todo, dinero, ropa, maletas e incluso la esperanza de unas bonitas vacaciones.' 
Lo mismo podemos decir del ej. 7, en el que cioè precede al verbo en infinitivo saper accogliere "saber acoger", que es lo más importante en la aclaración o explicación de lo que significa una "acogida plural", por lo que la siguiente traducción también sería adecuada:

7 bis. L'asilo nido deve essere in grado di garantire una accoglienza plurale, deve cioè sapere accogliere e mettere insieme bambini diversi che si trovano a svolgere insieme delle attività (giocare insieme, imparare, ecc.).

'La escuela infantil tiene que ser capaz de garantizar una acogida plural, es decir, lo más importante es que sepa acoger y coordinar a niños diferentes que tienen que desarrollar juntos distintas actividades (jugar, aprender, etc.).'

\subsubsection{Propiedades fónicas}

Cioè con valor reformulativo, en textos escritos, aparece precedido de punto, coma o punto y coma, pero también muy frecuentemente aparece sin ningún signo de puntuación que lo preceda. Del mismo modo, tras él, podemos encontrar una coma, mucho más raramente un punto o incluso, lo más frecuente, ningún signo de puntuación, mientras que los signos reformuladores explicativos 'es decir' y 'o sea' suelen destacarse siempre entre comas.

En textos orales, el cioè reformulador se percibe con un cuerpo entonativo que varía según el tipo de reformulación de la que se trate, objetiva o subjetiva, según quien lleve a cabo la reformulación (auto o heterorreformulación), dependiendo de si se explicita la reformulación o se deja implícita y, por supuesto, según el valor que asume el marcador en el contexto.

Puede incluso aparecer de forma autónoma, en un turno de palabra en frase interrogativa, cuando el interlocutor solicita al hablante una explicación o aclaración de lo que acaba de decir.

9. -Io, invece, penso che tu e il tuo amico potreste fare qualcosa.

-Cioè?

-Che ne so? Potresti fare un regalo a qualcuno, per esempio. (BT9)

'Yo, en cambio, creo que tú y tu amigo podríais hacer algo.

- Cioè l ¿̇ $O$ sea? - ¿El qué?

-¡Qué sé yo! Podrías regalarle algo a alguien, por ejemplo.'

\subsubsection{Eliminabilidad}

La posibilidad de suprimir el MD en un enunciado es una de las características de estos elementos. Con cioè es posible en unos casos, pero no en todos. Podría suprimirse en reformulaciones en las que se expresa una completa equivalencia con el segmento de referencia, en las que, además, es posible invertir el orden de los segmentos, como en el ejemplo siguiente: 
10. Maria, [cioè] tua sorella, studia con me all'università.

Tua sorella, [ciò̀] Maria, studia con me all'università.

'María, cioè / [o sea] tu hermana / Tu hermana, cioè / [o sea] María, estudia conmigo en la universidad.'8

Sin embargo, cioè no podría suprimirse en una reformulación en la que se rectifica o corrige lo que se ha dicho en el segmento de referencia, ni tampoco, en estos casos, podría invertirse el orden de los segmentos:

11. Verrò lunedì, cioè martedì.

'Vendré el lunes, cioè / mejor dicho, el martes.'

En algunos casos, aunque la supresión de cioè es completamente factible, es posible que se pierdan matices de distinto tipo, como en este caso donde, al eliminar $e$ cioè de su pregunta, realmente retórica, ya que más que preguntar lo que hace es amonestar.

12. Mi domando sempre una cosa e cioè: $\mathrm{xk}$ le ragazze che siamo robuste dobbiamo sempre essere prese in giro? (BT10)

'Me pregunto siempre una cosa e cioè /y es la siguiente: ¿por qué las chicas que somos gorditas tenemos siempre que aguantar que se burlen de nosotras, ¿̨eh?

\subsubsection{Comparecencia con otros marcadores}

Cioè puede aparecer junto con otros marcadores, sobre todo en textos orales o en textos escritos que reflejan el discurso oral (como chats o foros), formando cúmulos o cadenas ${ }^{10}$ que sirven como elementos de articulación interna en el discurso, como soporte conversacional ${ }^{11}$.

13. La parola, come dicevamo, è di origine ceca e deve conservare, per tanto, l'accentazione originaria; l'accento, insomma, cioè il "tono" della voce, deve cadere sulla prima "o" (ròbot). (BT11)

8 Se sobreentiende que se trata de un caso en el que el interlocutor tiene una única hermana.

9 No es infrecuente encontrar a cioè precedido de la conjunción $e$ (e cioè); respecto del cioè sin conjunción le añade un valor de cierta enfatización al que ya posee como reformulador (se trata de un fenómeno, con todo, que merece una atención más detenida). Esta presencia de la conjunción $e$ ratifica el valor adverbial de cioè.

${ }^{10}$ Se habla de cúmulos cuando, en la secuencia de los marcadores, todos desarrollan la misma función, normalmente la de riempitivi; el concepto de cadenas hace referencia a, cuando en la secuencia de varios marcadores, cada uno desarrolla una función específica (Bazzanella 2001: 81).

11 Para Durante (1981: 274 apud Serianni 1989: 458) "riflette quell'ansia di spiegare e di spiegarsi che è sinonimo di disponibilità al dialogo", refiriéndose a esta partícula incluso como símbolo del lenguaje juvenil entre los años sesenta y ochenta. 
'La palabra, como decíamos, es de origen checo y tiene que conservar, por tanto, la acentuación original; el acento, vamos, cioè / o sea el "tono", de la voz, tiene que caer en la primera 'o' (róbot).'

14. ah ecco... cioè i soldi del carburante che io pago fanno questa fine... bene bene, buono a sapersi! (BT12)

‘ah mira qué bien! Cioè / entonces - o sea el dinero que pago por el carburante va a parar aquí ¿̇no?, vale vale, es bueno saberlo...'

\subsubsection{Cioè ¿̇adverbio conjuntivo?}

Por lo que hemos ido comentado en los subapartados anteriores, por los ejemplos italianos en los que se han analizado distintas propiedades distribucionales o sintácticas de este elemento, y por las traducciones de este signo en español, podemos avanzar que, a pesar de que su valor es principalmente metatextual, sus funciones no se limitan exclusivamente a las de ossia o vale a dire, mucho más incidentales, sino que este elemento puede desarrollar también funciones similares -en algunos casos- a las de perciò, dunque o incluso insomma, infine o poi. Es decir, podemos sostener que se comporta como un adverbio conjuntivo de inferencia consecutiva; de ahí que pueda combinarse con las conjunciones (e cioè, véase ej. 12), que tenga amplia libertad distribucional (ejs. $4,5,6,7,8)$, y de que incluso pueda colocarse al final del enunciado (véase ej. 3 ).

\section{ESTATUTO LÉXICO DEL MARCADOR DISCURSIVO ITALIANO CIOĖ Y SU PROYECCIÓN EN LA CONSTRUCCIÓN DEL DISCURSO}

\subsection{La partícula cioè en los diccionarios}

El significado nuclear de cioè, como ya hemos indicado, es el de aclaración. En todos los diccionarios monolingües y bilingües consultados, el valor declarativoexplicativo es el primero que se recoge. Las distintas funciones que puede desempeñar nuestro marcador se reconducen, en la mayoría de los casos, a este valor principal declarativo-explicativo.

En los diez diccionarios monolingües consultados ${ }^{12}$ se señalan de dos a cuatro acepciones del término cioè. La primera función es la declarativo-explicativa, con definiciones de tipo sinonímico en las que se ofrecen expresiones sustitutivas de cioè para introducir una aclaración o explicación de lo que se acaba de expresar: intendo dire, vale a dire, in altre parole, ossia, ovvero, questo è; este valor puede aparecer reforzado con la expresión cioè a dire (procedente del francés 'c'est-àdire') y la recogen todos los diccionarios monolingües consultados. La segunda función señalada es la correctora; es decir, cioè puede emplearse para rectificar una afirmación anterior, $\mathrm{y}$ se ofrecen expresiones equivalentes de cioè con este

${ }^{12}$ S. Battaglia, T. De Mauro, G. Devoto y G. C. Oli, A. Gabrielli, G. Gabrielli, F. Palazzi, G. Pittàno, N. Zingarelli, Sabatini-Coletti, Treccani. 
valor como: ossia, ovvero, o meglio, (o) piuttosto, (o) per meglio dire (casi todos los diccionarios recogen este segundo valor -no lo hacen Palazzi ni Aldo Gabrielli-). La tercera función es la empleada por el interlocutor de forma autónoma (solo, en un turno de palabra) en frase interrogativa (Cioè?) para solicitar explicación o aclaración al emisor de lo que acaba de decir (lo recogen seis de los diez -no lo hacen Palazzi, Pittano, Aldo Gabrielli, Devoto y Oli-). El cuarto valor solo lo recogen dos de los diez diccionarios, y es la función enfática (así la llama De Mauro en el GRADIT) o función de marcador discursivo (así llamada en Sabatini-Coletti), y se refiere a la función desempeñada por cioè en momentos de duda o cuando el hablante está buscando la palabra adecuada o la manera de proseguir su discurso.

En los ocho diccionarios bilingües italiano-español consultados ${ }^{13}$, el valor declarativo-explicativo es el que todos recogen y dan como equivalentes en español las siguientes expresiones: esto es, eso es, a saber, es decir, o sea. El segundo valor de cioè que hemos señalado -el de corrector-, lo recogen solo tres de los ocho (Sañé y Schepisi, Espasa Paravia y Tam): mejor dicho, o mejor, o más bien son las distintas equivalencias en español que se ofrecen. El tercer valor que hemos señalado (en frase interrogativa) solo lo recoge Tam y da como equivalencias en español: ¿̇o sea?, ¿̇y qué? El último valor no lo recoge ninguno de los diccionarios bilingües consultados.

En este sentido, los diccionarios no siempre dan al estudiante de italiano/ L2 la ayuda que este necesita para entender el marcador y, de ahí, el texto en el que cioè aparece. No todos los diccionarios ofrecen ejemplos (de los diccionarios monolingües sí que los ofrecen ocho de diez; en cambio, de los bilingües, solo tres de ocho) y/o no se recogen todos los posibles usos.

\subsection{Indice de frecuencia de la partícula cioè}

La partícula cioè, como hemos apuntado en la introducción, presenta un índice de frecuencia muy alto en la lengua escrita y oral de hablantes nativos de italiano. En el volumen de Bortolini, Tagliavini y Zampolli (1972), que realiza un estudio de frecuencia de aparición de 5356 palabras a partir de la selección de 500000 palabras procedentes de textos escritos de distintos géneros, cioè figura en la posición 223 si consideramos la frecuencia (número de veces que aparece una palabra en el corpus) y en la posición 270 si consideramos el índice de uso (producto de la frecuencia por el coeficiente de dispersión -coeficiente que mide la uniformidad con que se reparten las apariciones de cada palabra en los distintos géneros considerados-), lo que nos indica que cioè es una de las palabras italianas más usadas. Asimismo, nuestro marcador aparece entre las 2000 palabras con mayor índice de uso en italiano en textos escritos, dentro

${ }^{13}$ L. Ambruzzi, C. Calvo y A. Giordano, S. Carbonell, L. Lavacchi y Mª C. Nicolás, E. M. Martínez Amador, S. Sañé y G. Schepisi, L. Tam, Espasa Paravia. 
del Vocabolario di base della lingua italiana (6700 palabras), elaborado por T. De Mauro en colaboración con S. Gensini y E. Passaponti (De Mauro 1980). En el Lessico difrequenza dell'italiano parlato di Tullio Di Mauro (1993), que realiza un estudio de frecuencia de aparición de 15478 palabras a partir de la selección de 500000 palabras procedentes de textos orales de distintos géneros, cioè figura en la posición 50 si consideramos la frecuencia y en la posición 51 si nos referimos al uso, lo que ratifica el amplio empleo de este marcador también en el registro oral, mayor incluso que en el escrito.

Sin embargo, la interlengua de aprendices hispanohablantes de italiano/ L2 muestra un empleo casi inexistente de esta partícula en los niveles iniciales $\mathrm{y}$ un uso escaso en los niveles intermedio y superior. En el trabajo de Guil (2010), referido al empleo de marcadores discursivos italianos por alumnos hispanofónos en el registro oral, el marcador cioè no es utilizado ni una sola vez por las alumnas de nivel inicial, sí en cambio en nivel intermedio y vuelve a decrecer en nivel avanzado. El empleo de cioè en el corpus de Guil es similar en cuanto a su empleo al de otros marcadores como poi o quindi, muy por debajo del uso de ok, ma (para iniciar el turno de palabra), d'accordo y allora (este en nivel avanzado principalmente), pero superior al de voglio dire, ecco, appunto, comunque, insomma, que son muy poco o nada utilizados.

Por nuestra parte, grabamos con una cámara de vídeo las intervenciones monologales libres de 43 alumnos estudiantes de italiano del Centro de Lenguas Modernas de la Universidad de Zaragoza (CULM), con una duración total de 2 horas y 40 minutos a lo largo del mes de mayo de 2012. De los 43 alumnos, 25 cursaban primer año (en el momento de la grabación podemos decir que poseían un nivel A2), 7 de cuarto curso (nivel B1+) y 11 del grupo Lingua e cultura italiana (B2). Tuvieron unos días para preparar sus intervenciones (la tarea se encargó de una semana para otra) y se pretendía que los alumnos hablasen con la mayor libertad posible sobre temas que les eran familiares y conocidos. Solo se registraron 3 usos de cioè, las 3 ocurrencias en el mismo alumno, perteneciente a un nivel superior (B2) y con uso expletivo.

Este uso reducido del marcador en aprendices hispanohablantes de italiano/ L2, frente al amplio uso del marcador por la población nativa, nos sugiere que se trata de un elemento que, posiblemente, presenta distintas dificultades en el aprendizaje del italiano/L2. Sería aconsejable una explicación en clase, tanto de su distribución en la frase (que es mucho más amplia que la de elementos similares en cuanto a la función en español) como de los valores que puede desempeñar y que hemos descrito y destacado, ya que no todos están recogidos en los principales diccionarios bilingües, lo cual dificulta especialmente su aprendizaje. 


\subsection{Tipología de textos en los que cioè puede aparecer}

Nuestra partícula, con valor reformulativo, aparece en una amplia tipología de textos, desde lenguaje coloquial (ej. 15 , procedente de un foro de internet) hasta textos periodísticos, científicos o jurídicos, como dejan ver los ejemplos 16,17 y 18:

15. Che paese è questo? Cioè, quando muore un famoso, dobbiamo far vedere a tutti che ci dispiace, anche se non sappiamo chi sia? (BT13) ¿Qué país es este? Cioè / O sea que cuando muere un famoso ¿̇tenemos que hacer ver a los demás que lo sentimos aunque no sepamos quién es o quê? 14

16. ...far vedere foto di modelle scheletriche accentuava la propensione a preferire la magrezza a tutti i costi -spiega Boothroyd-. Questo dimostra che le immagini "aspirazionali", in cui cioè si rappresenta un modello a cui farebbe piacere somigliare, hanno una forte influenza sulle nostre opinioni. (BT14)

‘[...] Esto demuestra que las imágenes "aspiracionales", en las cuales, cioè / por tanto se representa un modelo al que gustaría parecerse, tienen una fuerte influencia en nuestras opiniones - imágenes "aspiracionales", es decir, aquellas en las que...'

17. Come i correlati neurali della coscienza, cioè come queste configurazioni di attivazione neurale riescano poi a dare vita a pensieri, sensazioni, emozioni o così via rimarrà un enigma forse per molto tempo ancora. (BT15)

'Cómo los correlatos neurales de la conciencia, cioè / es decir, cómo estas configuraciones de activación neuronal logran después dar vida a pensamientos, sensaciones, emociones, etc. seguirá siendo un misterio todavía durante mucho tiempo.'

18. L'Unione europea esprime vivo apprezzamento per l'accordo raggiunto a Machakos (Kenya) in data 20 luglio 2002, tra il governo del Sudan e l'SPLM/A sulle due questioni maggiormente controverse, e cioè il diritto di autodeterminazione della popolazione del Sudan meridionale e lo Stato e la religione (Dichiarazione della Presidenza a nome dell'Unione europea sul Sudan). (BT16)

'La Unión europea expresa su satisfacción por el acuerdo alcanzado en Machakos (Kenia) en fecha de 20 julio 2002 entre el gobierno de Sudán y el SPLM/A en las dos cuestiones más controvertidas, e cioè / es decir, - que son el derecho de autodeterminación de la población del Sudán meridional y el Estado y la religión.'

${ }^{14}$ Otra traducción tal vez más adecuada estilísticamente: 'Pero ¿en qué país vivimos que cuando muere un famoso tenemos que hacer ver a los demás que lo sentimos aunque no sepamos quién es?’. 


\section{FUNCIONES METATEXTUALES DE CIOÈ: LA REFORMULACIÓN}

La función de cioè como indicador de reformulación es una de las más frecuentes, así como la más cercana a su significado conceptual de explicación. A través de marcadores de este tipo (insomma, cioè, be', diciamo, voglio dire), el hablante resume, explica, aclara, precisa, rectifica, ejemplifica su discurso previo en función de lo que considera necesario, en relación con sus intereses comunicativos o para ayudar al interlocutor en la correcta interpretación del enunciado. La reformulación la puede llevar a cabo el propio hablante (autorreformulación), como en los ejs. 19 y 20, o el interlocutor (heterorreformulación), como en los ejs. 21 y 22, este último con una doble heterorreformulación.

19. Quando arriva la vera estate? cioè voglio dire quando se ne va sta pioggia? (BT17)

‘Cuándo llega de verdad el verano? Cioè / O sea - En fin - Bueno, lo que quiero decir es que ¡¿cuándo se va ya esta lluvia de una vez?!'

20. In totale nei primi sei mesi del 2012 si sono trasferite nella Repubblica federale 501.000 persone, cioè 66.000 in più dello stesso periodo del $2011(+15 \%)$. (BT18)

'En total, en los primeros seis meses de 2012 han emigrado a la República federal 501000 personas, cioè / es decir, 66000 más que en el mismo periodo del año anterior $(+15 \%)$.'

21. -Voglio comprare il nokia lumia 920.

-Cioè tu vuoi spendere $650 €$ per un cellulare che non vale nemmeno la pena di spendergli 50€??? (BT19)

'-Quiero comprar el Nokia Lumia 920

-Cioè / O sea, iä[me estás diciendo] que - Cioè / ¿ique quieres gastarte 650 euros en un móvil que no vale ni siquiera 50 euros?!

22. -Addirittura minacce insomma, nei confronti di queste persone che sono state obbligate ad andare in pensione.

-Non sono state obbligate perché hanno firmato...

- Cioè Lei dice che questa cosa non è vera. Cioè che loro si sono inventati tutto? (BT20)

'-Vamos, se llegó incluso a amenazar a estas personas, que fueron obligadas a jubilarse.

-No se las obligó porque firmaron...

- Cioè / O sea ¿[me está diciendo] que - Cioè / ¿Que lo que le digo no es cierto, que estas personas se lo han inventado todo?'

Si lo que tenemos en cuenta es la conexión que establece el marcador entre los miembros relacionados, distinguimos la reformulación parafrástica (RP) (ej. 23) de la no parafrástica (RNP) ${ }^{15}$ (ej. 24). En la primera de ellas, el marcador

15 Siguiendo la distinción que establecieron Roulet (1987) y Rossari (1990). 
"establece una relación de identidad entre los miembros relacionados"; en la segunda, "el marcador permite reinterpretar el segmento que se reformula según una nueva perspectiva” (Garcés Gómez 2008: 72).

23. Il picco della crescita si toccherà però nel 2014, quando il saldo migratorio (la differenza cioè tra chi si trasferisce in Germania e chi la lascia) sarà di 506.000 persone. (BT21)

'Sin embargo, el pico de crecimiento tendrá lugar en 2014, fecha en la que el saldo migratorio (cioè / es decir, la diferencia entre el número de personas que entran y salen de Alemania), será de 506000 personas.'

24. Io non sono assolutamente andato volontariamente. Io facevo un lavoro molto interessante, molto importante, avevo dei progetti grossi che portavo avanti molto bene, avevo sbloccato delle situazioni incancrenite da anni... Tra l'altro, la carta era già compilata. Cioè io sono entrato nel suo ufficio, mi è stata messa sotto il naso, mi è stato detto devi firmare perché se non firmi, avrai dei problemi. (BT22)

'Yo no fui en absoluto de forma voluntaria. Yo estaba haciendo un trabajo muy interesante, muy importante, estaba sacando adelante grandes proyectos, había desbloqueado situaciones que estaban enquistadas desde hacía tiempo... Además, el documento ya estaba cumplimentado. Cioè / En definitiva - en resumidas cuentas - en resumen - en fin, yo entré en su despacho, me puso el documento delante de las narices y se me dijo "tienes que firmar porque, si no firmas, tendrás problemas".'

No obstante, para la presentación de los distintos tipos de reformulación que podemos encontrar vehiculados por cioè, hemos preferido hablar de reformulación objetiva y subjetiva mejor que de RP y RNP ${ }^{16}$, entendida la reformulación objetiva como una formulación nueva en la que se vuelve sobre lo formulado con

16 Fuentes Rodríguez (1993) distingue, dentro de la RP, la explicación, la denominación y la corrección y, dentro de la RNP, dos subtipos: por condensación (la etiqueta, la conclusión y la recapitulación) y por extensión (la enumeración y la ejemplificación). Bazzanella (1995) distingue tres fenómenos dentro de la reformulación: la paráfrasis, la corrección y la ejemplificación. Como vemos, la corrección se halla dentro de la RP en un caso y fuera de ella en otro.

Para Gülich y Kotschi (1995), los procedimientos de corrección se integran en el proceso de RP, aunque posteriormente Kotschi (2001) ya no incluirá la corrección en la RP porque, o bien la expresión de reformulación queda eliminada de la memoria discursiva o bien el hablante desea suprimirla. Como señaló Kotschi (1997) apud Garcés Gómez (2008: 72), los criterios planteados para distinguir la RP de la RNP plantean problemas, ya que también en la RP puede haber reinterpretación del significado (en los de corrección, por ejemplo) y porque en la RNP puede haber identidad entre los miembros reformulados (en los recapitulativos, por ejemplo). Asimismo Hossbach (1997) señala procedimientos de reformulación que poseen rasgos tanto de la RP como de la RNP, proponiendo una zona intermedia donde estarían incluidos el resumen y la recapitulación. La dificultad que presentan las distintas caracterizaciones, como señala Garcés Gómez (2008: 74), se debe a los criterios que se manejan para definir cada uno de los tipos: semánticos y pragmáticos en el caso de la RP, y únicamente pragmáticos en el caso de la RNP. 
el deseo de explicarlo, matizarlo, aclararlo, corregirlo, pero con independencia de la manera de pensar o sentir del hablante (cf., más adelante, la nota 23, sobre el texto de Ferrini). Dentro de este tipo de reformulación objetiva (imparcial, ajustada a lo real), podemos encontrar el MD cioè para:

- marcar la explicación de un término culto o término técnico con formantes clásicos:

25. Da un punto di vista clinico la malattia è simile a quella da virus $\mathrm{A}$, ma la fase postitterica (epatomegalia cioè ingrossamento del fegato ed elevazione degli enzimi epatici) è più lunga, raggiungendo le 10-12 settimane. (BT23)

'... hepatomegalia, cioè / es decir, agrandamiento del hígado y aumento de las enzimas hepáticas...'

- traducir a la lengua meta una palabra extranjera (traducción interlingüística), que viene a ser otro tipo de explicación o aclaración:

26. «Umu», cioè «giorno». In assiro-babilonese. (BT2)

'«Umu», cioè les decir, «día». En asiriobabilónico.'

- explicar un préstamo (en cosmética, en este caso), que se aclara:

27. Punta su un lipstick colore bois de rose (cioè tra il rosso e il rosato).

Evidenzia il sorriso e nasconde la spossatezza. (BT 24)

'Apuesta por un pintalabios color bois de rose (cioè / o sea, entre el rojo y el rosado). Resalta la sonrisa y disimula el cansancio.'

- explicar un neologismo o una expresión de cuño relativamente reciente (como coppie di fatto / 'parejas de hecho'):

28. Attualmente in Italia non esiste nessuna legge per stabilire i diritti e i doveri delle "coppie di fatto", cioè delle persone che da anni vivono insieme senza essere sposate. (BT25)

'[...] "parejas de hecho", cioè / es decir, las personas que viven juntas desde hace años sin estar casadas.'

Aunque, como vemos, la glosa (o traducción intralingüística) de una misma expresión es ligeramente diferente según el emisor que se ocupe de explicar el término, focalizando su nueva formulación en un aspecto más que en otro:

29. Tuttavia il fenomeno delle "coppie di fatto", cioè conviventi etero o/e omosessuali, in Italia hanno avuto negli ultimi anni uno sviluppo... (BT26)

'[...] "parejas de hecho", cioè / es decir, personas que conviven, tanto heterosexuales como homosexuales,'...

30. In occasione della Giornata mondiale delle Famiglie [il sindaco Giuliano Pisapia] chiederà un'udienza al Papa per parlare delle coppie di fatto, cioè «della famiglia intesa come nucleo affettivo». (BT27) '[...] para hablar de las parejas de hecho, cioè / es decir, de «la familia entendida como núcleo afectivo»' 
- concretar algo enunciado en el miembro de referencia que el hablante considera que no está lo suficientemente claro (i soggetti più deboli):

31. Lofferta è nata da una trattativa sbrigativa, quasi da mercato, e sembra fatta apposta per approfittare dei soggetti più deboli, quelli, cioè, che hanno perso tutto, soldi, vestiti, valigie ed anche la speranza di una bella vacanza. (BT6)

'La oferta surgió de una negociación apresurada, casi mercantil, y parece hecha a posta para aprovecharse de los individuos más débiles, aquellos, cioè / es decir - pues, que lo han perdido todo... [...los individuos más débiles, cioè / es decir, los que lo han perdido todo, dinero, ropa, maletas e incluso la esperanza de unas bonitas vacaciones].'

- hacer algo más explícito al interlocutor; en el ej. 32, una pregunta que se le acaba de formular de forma genérica o, en el ej.33, un término que puede resultar polisémico y del que se aclara la acepción:

32. Come funziona, cioè dove si attacca?? (BT28)

'CCómo funciona? Cioè / O sea, ¿dónde se enchufa?'

33. Javier Pastore detto el Flaco cioè il malato. (BT29)

'Javier Pastore, el Flaco, cioè / es decir, el flojo'. ${ }^{17}$

- denominar a la persona de la que se habla, como en este caso:

34. ...senza che il legale rappresentante, che era anche l'amministratore della Fininvest, cioè Berlusconi, lo sapesse e lo accettasse. (BT30)

'...sin que el representante legal, que era también el administrador de Fininvest, cioè / o sea Berlusconi, lo supiese y lo aceptase.'

- ejemplificar lo que se ha dicho en el segmento de referencia:

35. ...noi ragazzi invece provvediamo, no, così alla dimensione artigianale no, cioè tutti lavoretti così, in ceramica, in cuoio, no, così eccetera... (BT31)

'los chicos, en cambio, nos ocupamos ¿no? de la dimensión artesanal, ¿no?, cioè / o sea, de trabajitos de esos, de cerámica, de cuero, ¿no?, vamos, trabajitos de ese tipo...'

- explicitar una presuposición o una inferencia (que el oyente puede deducir discursivamente de lo que se ha dicho en el segmento de referencia), como en el siguiente ejemplo, un titular de un artículo periodístico:

36. «Licenziate o sottopagate, cioè donne»18

Sul lavoro femminile stiamo messi peggio di Nicaragua, Maldive e Honduras. Basterebbe solo questo per demoralizzarsi leggendo l'indice globale del Gender Gap elaborato a livello mondiale dal

${ }^{17}$ Con lo que se especifica que no se hace referencia a la primera acepción de 'flaco' 'con pocas carnes', sino a la de 'flojo', 'endeble', 'sin fuerzas'; de hecho este futbolista italoargentino que juega en el Palermo ha sufrido varios episodios en los que ha estado en baja forma y con lesiones musculares.

${ }^{18}$ Indicamos con comillas angulares que se trata de un titular. 
World Economic Forum, dove l'Italia è piazzata al 94 posto su 134 nazioni prese in esame. (BT32)

'Despedidas o malpagadas, cioè / o sea mujeres.'19

- explicitar una implicación (algo que está implítico o contenido en el segmento de referencia) y que solo conoce el hablante:

37. Ha dimenticato solo una cosa, cioè di guardarsi allo specchio. (BT33)

'Ha olvidado solo una cosa, cioè / es decir - esto es: mirarse en el espejo.'20

- explicitar lo que está contenido en el primer segmento por un numeral (o cualquier otro elemento lingüístico con función catafórica) ${ }^{21}$ :

38. Le cadenze sono tre, cioè semplice, composta, e doppia. (BT34)

'Las cadencias son tres, cioè / a saber: simple, compuesta y doble.'

En unos casos, como estamos comprobando en los ejemplos, la reformulación no supone variación en cuanto al tamaño de los miembros relacionados, en otros, supone una reducción respecto a lo expresado anteriormente y, en otros que suele ser lo más frecuente-, el segmento reformulado es una expansión del de referencia.

Como vemos, estamos yendo de la equivalencia más absoluta entre el segmento de referencia y el segmento reformulado a reformulaciones, que vamos a ver ahora, en las que se lleva a cabo una corrección de lo dicho en el segmento de referencia, con ejemplos que van desde una matización (ej. 39), o una parcial rectificación de lo dicho (ej. 40), hasta una rectificación mayor (ej. 41). En cualquier caso, en la reformulación ha tenido lugar una modificación, bien en la designación, en el sentido o en ambos, lo que hace que sea el segmento reformulado el que determine la prosecución del discurso, es decir, la reformulación, en este caso, no implica simplemente retomar lo dicho formulándolo de otro modo que se quiera equivalente, sino que conlleva la inclusión de una formulación distinta, conscientemente modificadora de la precedente.

39. Il premier uscente, cioè uscito, preparò un congedo diverso, più incisivo e veritiero. (BT35)

'El primer ministro saliente, cioè / mejor dicho, el exprimer ministro, preparó una despedida distinta, más incisiva y sincera.' (hablando de

19 Otra traducción tal vez más adecuada estilísticamente: 'Despedidas o malpagadas, nos referimos, obviamente, a las mujeres'.

${ }^{20}$ Otra traducción posible del cioè en los ejs. 37 y 38 podrían ser únicamente los dos puntos.

21 Casado Velarde (1991: 110-1) habla de dos tipos de explicación o de evidenciación: la reformulación de lo dicho y la explicitación de lo no dicho. Dentro de este segundo tipo, distingue la explicitación de la presuposición (de lo que se deduce discursivamente de algo que se sabe, ej. 36) de la explicitación de la implicación (de aquello que está implícito en un enunciado y que solo conoce el hablante, por lo que no se trata de introducir una expresión más inteligible o clara para el oyente sino de comunicar algo que este desconoce), distinguiendo tres casos dentro de ella: general (simplemente se explicita lo que no está anunciado, ej. 37); de ponderación o intensificación (que veremos cuando tratemos la reformulación subjetiva) y de enumeración (ej. 38). 


\section{Berlusconi)}

40. Non sono d'accordo. Cioè, sì, hai ragione, però non avrebbe mai potuto espellere qualcuno nel primo tempo di una finale Mondiale, a meno di pugni o gomitate 22 . (BT36)

'No estoy de acuerdo. Cioè / Bueno, vale - Quiero decir, sí, tienes razón, pero no habría podido expulsar nunca a nadie en el primer tiempo de la final de un Mundial, salvo por puñetazos o codazos.'

41. Ma poi torno martedì, cioè mercoledì mattina, volando la notte. (BT37)

'Pero después vuelvo el martes, cioè / mejor dicho - digo el miércoles por la mañana, porque vuelo por la noche.'

Además de los distintos casos de reformulación que hemos ido viendo hasta ahora (reformulaciones objetivas, podríamos decir reales, verificables, universalmente válidas), cioè puede encabezar una reformulación subjetiva ${ }^{23}$, es decir, una formulación nueva en la que se vuelve sobre lo formulado con el deseo de explicarlo, matizarlo, aclararlo, corregirlo, pero en la que interviene la manera de pensar o sentir del emisor. Dentro de este segundo tipo de reformulación (reformulación subjetiva), podemos diferenciar distintos casos:

- cuando el emisor muestra de forma explícita que su reformulación es subjetiva, reflejando su actitud ante lo expresado, como en los ejemplos siguientes, donde la reformulación contiene otros elementos modalizadores en los que está clara la implicación del emisor en lo que dice (voglio dire en los ejs. 42 y 43, francamente io en el ej. 44, adjetivo en grado superlativo bruttissimo en el ej. 45):

42. Quando arriva la vera estate? cioé voglio dire quando se ne va sta pioggia? (BT17)

¿Cuándo llega de verdad el verano? Cioè / O sea - En fin - Bueno, lo que de verdad quiero saber es ¡¿cuándo se va ya esta lluvia de una vez?!

43. Di bere non ho voglia. Cioè, voglio dire, magari la voglia cèe, ma non ho più una lira per poterlo fare. (BT38)

\footnotetext{
${ }^{22}$ En este caso, cioè se utiliza con una función también modalizadora (dentro de las funciones cognitivas que también puede asumir este marcador), es decir, como estrategia de cortesía negativa, para mitigar la fuerza inlocutiva del segmento recién formulado por el hablante, que se opone a lo defendido por su interlocutor. En Martín Zorraquino y Portolés (1999: 4143-4) se hace referencia a la relación existente entre los marcadores metadiscursivos conversacionales y los marcadores de reformulación, así como al despliegue de estrategias que señalan el papel del hablante respecto de su interlocutor, como se ve en este ejemplo.

${ }^{23}$ En la clara monografía sobre cioè de S. Ferrini (1985: 50-53), la autora ya apunta que la explicación introducida por cioè puede ser de valor objetivo y de valor subjetivo. Señala que el valor objetivo de la explicación puede estar subrayado por la forma cioè a dire $\mathrm{y}$, para subrayar la subjetividad de la explicación encabezada por cioè, esta partícula puede estar acompañada por las formas voglio dire o intendo dire.
} 
'Beber... no tengo ganas. Ciò̀ / O sea - Bueno, quiero decir que - La verdad es que ganas a lo mejor sí que tengo pero no tengo un duro para poderlo hacer.'

44. -Che ne pensate dell'ecografia in $3 \mathrm{D}$ ? Io non l'ho fatta per il primo figlio ma questa volta mi piacerebbe. Ho letto che però non è sicura al $100 \%$. Che ne pensate?

-Uno paga di più solo per vedere "una ricostruzione probabilistica del visino del pupo".... cioè francamente io in un'ecografia preferisco che sia tutto a posto e non una ricostruzione probabilistica. (BT39)

‘¿Qué pensáis de la ecografía en 3D? Yo no me la hice con el primero pero ahora me gustaría, aunque he leído que no es segura al 100\%. ¿Qué opináis?

-Uno paga más solo por ver "una reconstrucción probable de la carita del bebé”... cioè / bueno - o sea - la verdad, yo, francamente, en una ecografía prefiero que esté todo bien y no que sea una reconstrucción probable.' (de lo que se infiere una conclusión que, por lo clara que es, no se formula: yo no me haría la ecografía en 3D hasta que no fuera completamente fiable).

45. Yahoo Answer è noioso o sbaglio? Cioè è bruttissimo e ci vuole 3 ore per fare domande e altrettante 1000 per riceverne risposta. (BT40) 'Yahoo Answer es aburrido ¿̇o me equivoco? Cioè / O sea-Para mí es horroroso - A mi me parece horroroso, te pegas tres horas para hacer la pregunta y otras tantas para recibir la respuesta.'

O cuando el hablante, aun queriendo ser objetivo, deja ver que tiene dificultades en la expresión de lo que quiere decir, ya sean dificultades de tipo léxico-sintáctico (es decir, en la formulación lingüística de sus ideas) o dificultades pragmáticas (es decir, en la adecuación de la formulación del mensaje a su auditorio ${ }^{24}$ :

46. allora cioè non so come spiegarlo... aiutatemi (BT42) 'pues, cioè / o sea - la verdad, no sé cómo explicarlo... ayudadme'

47. Allora, in pratica, cioè... va beh cioè, allora, in pratica è successo... aspettate, rewind. Ecco. Dicevo. Quella sera i miei genitori avevano fatto quello, quello che... (BT43)

'Entonces, lo que pasó, cioè / o sea,... bueno pues, cioè / a ver, entonces, en resumidas cuentas pasó que... esperad, que vuelvo a empezar. Pues eso, decía que esa tarde mis padres habían hecho eso, lo que...'

- También es subjetiva, en principio, la heterorreformulación, ya que, en

${ }^{24}$ Estos usos los consideramos distintos del cioè expletivo, que sirve como simple muletilla o apoyo en la elocución, como en este ejemplo: Cioè... sì ...ma... sai... il telefonino... cioè... è una parte molto ma proprio molto... cioè importante per noi giovani e quindi cioè non ci può cioè essere tolto no? (BT41) 'Cioè / O sea-Bueno...vale... pero ¿sabes? el móvil cioè / ¿̇no? es una parte muy pero que muy cioè / o sea muy importante para los jóvenes y, por eso, įsabes? no se nos puede quitar ¿no?’ 
estos casos, es el interlocutor quien interpreta lo dicho por el emisor, pidiendo normalmente a este una confirmación de que su comprensión ha sido la adecuada ${ }^{25}$ :

48. -(LM) Ci sono diversi modi sui quali si può rispondere.

-(BI) Cioè quali sono?

-(LM) Si può rispondere per iscritto, si può rispondere attraverso gli assessori competenti, ci sono diversi modi, non è detto che...

-(BI) Cioè Lei in qualche modo ha risposto alle domande dei consiglieri.

-(LM) Ci sono diversi modi ripeto con i quali si può rispondere, non è detto che si debba rispondere nei tempi nei quali vengono fatte le domande.

-(BI) Cioè fino ad adesso non ha risposto Lei comunque, non sta rispondendo neanche a quello che Le ho chiesto io... (BT44)

'[...] (LM) Se puede responder por escrito, se puede responder a través de asesores competentes, hay distintas maneras, en ningún sitio dice que...

-(BI) Cioè / O sea, usted, de alguna manera ha respondido a las preguntas de los consejeros ¿̇no?

-(LM) Se puede responder, repito, de distintas maneras, en ningún sitio pone que se tenga que responder en el momento en el que se formulan las preguntas.

-(BI) Cioè / Entiendo, por tanto, que hasta el momento, en cualquier caso, usted no ha respondido i̇no?, como tampoco está respondiendo a lo que yo le he preguntado...'

- En otros casos, la reformulación subjetiva es valorativa, como en el siguiente ejemplo, procedente del titular de una noticia de periódico, que encabeza toda una argumentación a favor del primer ministro Monti frente a su predecesor Berlusconi:

49. «Monti, cioè sobrio»

25 Este ejemplo es la transcripción de un fragmento de la entrevista televisiva que Bernardo Iovene (BI) hizo a Letizia Moratti (LM), alcaldesa de Milán desde 2006 a 2011 (en el año 2006 se presentó como candidata por Forza Italia), que fue emitida en el programa 'Report' de la RAI el 19 de noviembre de 2006. Se trata de un ejemplo especialmente interesante, pues nos encontramos con tres cioè. El primero de ellos desempeña una función metacomunicativa (solicitud de aclaración al hablante por parte del interlocutor: se le pide que aclare lo que ha anticipado y no ha dicho); este cioè no está en negrita porque no se trata de un cioè reformulador y, también por eso, hemos ofrecido la traducción a partir del segundo cioè; el segundo y el tercero introducen dos heterorreformulaciones y, como se observa al leer todo el texto en el seno de la situación comunicativa - una entrevista en la que el entrevistador (BI) pone entre las cuerdas a su entrevistada (LM)-, el tercer cioè introduce una reformulación más acertada que la encabezada por el segundo cioè. 
È questo l'aggettivo più usato per definire il nuovo premier. E 'sobrio' è il contrario di ubriaco. Quindi, se le parole sono importanti, il riferimento è ai 15 anni di sbornia berlusconiana. $\mathrm{E}$ a due modelli antropologici opposti. (20/12/2011) (BT45)

'Monti, cioè / es decir la sobriedad - Monti o la sobriedad'26

La cualidad de sobrio es la más utilizada para definir al nuevo primer ministro y ‘sobrio' es lo contrario de borracho. Por tanto, si las palabras son importantes, la referencia es a los 15 años de borrachera berlusconiana y a dos modelos antropológicamente opuestos.'

frente a una reformulación objetiva con el mismo tópico (Monti), que vemos en este otro ejemplo:

50. Le elezioni le considera un orpello fastidioso. Così a New York mister Mario Monti, cioè il capo del governo italiano, ha fatto sapere che se glielo chiedessero sarebbe disposto a un secondo mandato, ma senza passare per la sfida delle urne. (BT46)

'Las elecciones las considera un oropel molesto. Así, en Nueva York, el señor Mario Monti, cioè / o sea, el jefe del gobierno italiano, ha declarado que si se lo pidiesen estaría dispuesto a un segundo mandato, pero sin pasar por el desafío de las urnas.'

- Otro ejemplo de reformulación subjetiva lo encontramos en el siguiente ejemplo, en el que cioè aparece en el título del discurso del Papa Benedicto XVI en la asamblea plenaria del Pontificio Consejo para los laicos (25/11/2011):

\section{Laici, cioè cristiani (BT47)}

'Laicos, cioè / es decir, cristianos'

Cioè no encabeza una explicación del término 'laico', ya que, en cualquier caso, dentro del lenguaje de la Iglesia, 'laico' sería un subgrupo de cristiano, un hipónimo, como lo sería 'aragonés' respecto de 'español'. ¿Qué se pretende, pues, con una aparente relación de equivalencia establecida por cioè? Sin duda, resaltar la importancia de este subgrupo (algo así como "cristianos de primera") y colocarlo en el mismo rango de importancia de sacerdotes o religiosos, es decir, no hablaríamos de una equivalencia semántica (de significado) sino pragmática. Tanto en este ejemplo como en el ej. 49, al establecer dichas relaciones de equivalencia, se hace evidente una operación argumentativa de clara intencionalidad ${ }^{27}$.

- En otros casos, bajo reformulaciones aparentemente objetivas, se esconde otro tipo de relaciones lógicas entre los segmentos enlazados

${ }^{26}$ En nuestra traducción ('Monti o la sobriedad') hemos optado por la transposición como procedimiento de traducción (un sustantivo 'sobriedad' en lugar del adjetivo 'sobrio').

27 Como sostiene Bach Martorell (1996), reformular raras veces constituye una operación argumentativa aséptica. 
por cioè, por lo que ya no estaríamos ante un reformulador puro sino ante un conector. Podemos decir que nuestro marcador se ha enriquecido de otros valores que surgen de sus usos en la heterorreformulación subjetiva, es decir, a través de su papel de marcador de hererorreformulador subjetivo, cioè posibilita una traslación de significados con repercusión sintáctica que permite al hablante establecer una conexión entre lo dicho y lo inferido, comportándose como un conector adverbial conjuntivo de tipo inferencial principalmente consecutivo. Estas relaciones, como decimos, pueden ser de distinto tipo:

consecutivo, como se aprecia en el siguiente ejemplo procedente de la entrevista televisiva entre Letizia Moratti (LM) y el periodista Bernardo Iovene $(\mathrm{BI})^{28}$, en el que cioè introduce una consecuencia de lo dicho anteriormente que, aunque queda implícita, resulta evidente:

52. -(BI) Che erano persone di 58 anni e sono stati costretti ad andare in pensione $[\ldots]$

-(LM) I prepensionamenti sono prepensionamenti concordati. Quindi non si prepensiona nessuno senza accordo...

-(BI) Sotto ricatto?

-(LM) Io le chiedo scusa, ma... veramente... vorrei che Lei non usasse questa parola nell'ambito della mia registrazione.

-(BI) Guardi, il Giudice delle indagini preliminari ha usato addirittura "violenza privata". Cioè... (BT48)

'...(BI) Mire, el juez que se ocupó de las pesquisas preliminares llegó incluso a hablar de "violencia privada", cioè / por lo tanto... / así que... / conque... [no me diga usted que no puedo emplear la palabra 'chantaje].'29.

conclusivo, como se observa en el siguiente texto publicitario:

${ }^{28}$ Los ejs. 22, 24 y 48 son también fragmentos de entrevistas procedentes del programa televisivo 'Report' de la RAI entre estos dos protagonistas, aunque se trata de entrevistas de fechas distintas.

${ }^{29}$ Traducimos, a continuación, todo el ejemplo para dar a conocer el contexto en el que se halla el segmento en el que aparece cioè: '-Que eran personas de 58 años y fueron obligadas a jubilarse... -Las prejubilaciones son prejubilaciones acordadas. Por tanto, no se prejubila a nadie sin acuerdo... ¿¿Con amenaza de chantaje? -Perdone pero..., sinceramente... querría que usted no utilizase esta palabra mientras dure esta entrevista. -Mire, el juez que se ocupó de las pesquisas preliminares llegó incluso a hablar de "violencia privada", cioè / por lo tanto... - asíque... - conque... 
53. Robusto, resistente, affidabile, cioè perfetto. Cosa ho comperato? Ma Whirlpool naturalmente, il modello ARZ 505/G, due compressori, ECO economizzatore per il freezer... (BT49)

'Sólido, resistente, fiable, cioè / en definitiva, perfecto. ¿Qué he comprado? Pues un frigorífico Whirlpool, por supuesto...'

aditivo, en el siguiente ejemplo, en el que cioè presenta el segundo miembro discursivo como un argumento con mayor fuerza que el primero:

54. Le riserve globali di cibo continuano a diminuire e la popolazione mondiale continua ad aumentare: al ritmo attuale di sfruttamento delle risorse (acqua e terra, in particolare) - afferma il SIWI - nel 2050 scoppieranno carestie e guerre per il cibo e, soprattutto, per l'acqua senza la quale non esisterebbe nulla di commestibile sul pianeta. La risposta al problema (e l'esortazione) degli studiosi di Stoccolma è molto semplice: il mondo deve cambiare regime alimentare al più presto, per evitare conflitti sociali dalle conseguenze imprevedibili e nefaste. La nostra dieta deve cambiare, cioè dobbiamo diventare tutti vegetariani (o quasi). (BT50)

'Nuestra dieta tiene que cambiar, cioè / es decir - es más, tenemos que hacernos todos vegetarianos (o casi vegetarianos). ${ }^{30}$

$>$ adversativo o contraargumentativo:

55. Pirati in mare. Nel Corno d'Africa? No. Cioè sì... a Napoli! (BT51) 'Piratas en el mar. ¿En el cuerno de África? No. Cioè / En definitivaBueno sí... en Nápoles.'

$>$ reforzativo:

56. Eh, non lo so, proprio un ambiente... un ambiente squallido in assoluto, guarda, brutto brutto brutto, cioè brutto, diverso da quello che uno s'aspetta in un campionato di serie "B", no? 31 (BT52)

30 Traducimos, a continuación, todo el ejemplo para dar a conocer el contexto en el que se halla el segmento en el que aparece cioè: 'Las reservas globales de alimento siguen disminuyendo y la población mundial sigue aumentando: con el ritmo actual de explotación de los recursos (agua y tierra principalmente) -sostiene el SIWI- en 2050 se sufrirán carestías y estallarán guerras por causa de la comida y, sobre todo, por el agua, sin la que no existiría nada comestible en el planeta. La respuesta al problema (y la exhortación) de los expertos de Estocolmo es muy clara: el mundo tiene que cambiar de régimen alimentario lo antes posible para, de este modo, evitar conflictos sociales de consecuencias imprevisibles y nefastas. Nuestra dieta tiene que cambiar, cioè / es decires más, tenemos que hacernos todos vegetarianos (o casi vegetarianos).'

31 Se trataría de una explicitación de ponderación o intensificación según Casado Velarde (véase nota al pie número 21), en la que cioè introduce el segmento en el que se pondera o intensifica el primer segmento a través de la repetición. 
'Humm, no lo sé, la verdad es que se respiraba un ambiente... un ambiente completamente deprimente, te lo digo en serio, feo, feo, feo, cioè / lo que se dice feo, muy distinto de lo que uno ¿̇verdad? se esperaría en un campeonato de segunda división.'

\section{CONCLUSIONES}

A lo largo de nuestro trabajo, tras una presentación de las principales características sintácticas y léxicas de cioè, hemos pasado a exponer los distintos tipos de reformulación que podía presentar la partícula, distinguiendo por un lado a) la autorreformulación de la heterorreformulación, según quien lleve a cabo la operación de reformular, el emisor o el interlocutor; b) la parafrástica de la no parafrástica, según el tipo de predicación que se establezca entre los miembros relacionados, de equivalencia en el primer caso y con un cambio de perspectiva en el segundo, si bien, hemos preferido centrar nuestra exposición en la distinción entre c) reformulación objetiva y reformulación subjetiva, basándonos para ello en el hecho de que la nueva formulación fuese independiente o revelase la manera de pensar o de sentir del hablante.

De lo explicado, se deriva que, con cioè, toda reformulación llevada a cabo por el interlocutor (heterorreformulación) es principalmente subjetiva, y que la llevada a cabo por el hablante puede ser tanto objetiva como subjetiva; que la reformulación no parafrástica es subjetiva y la reformulación parafrástica puede ser objetiva y subjetiva (por lo que, si estamos ante una reformulación objetiva, esta será siempre parafrástica).

Dentro de cada uno de estos dos tipos principales de reformulación, objetiva y subjetiva, también hemos diferenciado distintos casos. En la reformulación objetiva, un primer grupo donde hablamos de reformulación en sentido estricto, cuando cioè introduce el segundo segmento para explicar (un término culto, préstamo, neologismo, traducción de un término extranjero), aclarar, explicitar, denominar, ejemplificar o corregir lo formulado en el segmento de referencia, y un segundo grupo en el que cioè encabeza el segmento que se ocupa de explicitar lo no dicho, ya sea una presuposición o bien una implicación. Dentro de la reformulación subjetiva, hemos diferenciado, asimismo, distintos casos: el primero, cuando tanto el emisor como el interlocutor muestran de forma explícita que sus reformulaciones son subjetivas; un segundo grupo, representado por reformulaciones valorativas y, un último grupo, en los que, bajo una aparente reformulación, cioè actúa como conector, estableciendo vinculaciones semánticas y pragmáticas entre los miembros conectados (de tipo consecutivo, conclusivo, aditivo, adversativo y reforzativo). En la reformulación subjetiva, como hemos podido apreciar en los ejemplos comentados, estamos más cerca de funciones cognitivas que propiamente metadiscursivas.

Como hemos apuntado en este trabajo, suscribiendo lo dicho por Montolío Durán (1998: 114), buena parte de las dificultades en el empleo de los 
marcadores discursivos por parte de un hablante no nativo reside en el hecho de no poder siempre caracterizar estos elementos desde el punto de vista de su significado. Este hecho también supone un problema cuando queremos abordar su enseñanza en el terreno del italiano L2, que puede verse favorecida usando un enfoque contrastivo con la lengua materna del aprendiz (en nuestro caso, el español), como ya señaló Calvi (1995: 74). También estos elementos ofrecen dificultades en el campo de la traducción, como ya señalaron Mara (1986) o Borreguero (2011). No existen equivalentes perfectos entre dos lenguas, es decir, en buena parte de los ejemplos analizados, la traducción de cioè corresponde a un 'o sea' o a un 'es decir', pero aun habiendo correspondencia semántica, puede que no la haya desde el punto de vista de la sintaxis o de la distribución en la frase o no coincidan la frecuencia de uso en una y otra lengua, o los registros de uso no sean coincidentes. Lo importante es analizar los mecanismos que nos ofrece la lengua meta para comunicar lo mismo que la lengua de partida y para lograr las mismas inferencias, es decir, para comunicar semántica y pragmáticamente lo mismo.

Una presentación de los valores o efectos de sentido de esta partícula en abundantes y diferenciados contextos reales de uso, con las correspondientes traducciones al español, permite al alumno, por un lado, comprender cuál es / cuáles son los verdaderos significados que puede transmitir esta partícula, su libertad distribucional, sus colocaciones en la frase según lo que el hablante quiera transmitir y, por otro, comprobar cómo las posibles traducciones de este elemento cuando se emplea como reformulador no se limitan únicamente a las que recogen los diccionarios, sino que, dependiendo del contexto, su ubicación en la frase, la intención del hablante, o el registro empleado, pueden ser, además de 'es decir' u 'o sea', también otras como: 'quiero decir', 'es más', 'dicho de otro modo', 'mejor dicho', 'digo', 'en definitiva', 'en resumidas cuentas', 'a saber', 'pues', 'por lo tanto', 'así que', 'la verdad es que', 'bueno', 'vale', 'en fin', 'o', 'y, lo más importante (es que)', ‘'el qué?’, dos puntos, e incluso, en algunos casos, no traducirlo.

Habría más implicaciones de tipo didáctico, puesto que los ejemplos presentados (56) no se limitan a reformulaciones que implican una equivalencia perfecta entre los dos segmentos, sino que, bajo aparentes expresiones equivalentes, se esconden relaciones de distinto tipo que convendría que el alumno descubriese, para lo cual se lo podría invitar a que ejercitase con los marcadores desde distintos puntos de vista: eliminándolos y viendo qué efectos de sentido o qué valores se pierden, conmutándolos con partículas de significado equivalente (Arriveremo il 15 marzo, cioè domani, / ossia, quindi; $\grave{\mathrm{E}}$ un film molto bello, cioè bellissimo / anzi; Sono venuti Pietro, Laura, Federica, cioè tutto il gruppo / insomma; -Pietro e io ci siamo lasciati dopo 15 anni di matrimonio -Cioè? / Ossia?; Era come una struttura amministrativa, cioè dotata di uffici e sale convegni / quindi; Cioè sei stato o non sei stato tu a farlo? / dunque), contrastando 
aquellos aspectos que puedan tener en común o que los diferencien (semánticos, de distribución, etc.).

Ciertamente reformular supone un dominio de la expresión que no está al alcance de un nivel inicial, ya que el alumno, en este primer nivel, tiene suficiente con saber expresarse (con formular), mientras que, cuando reformula, debe escoger otra manera de expresar lo que ha dicho, modificando normalmente la forma, pero sin cambiar, en la mayoría de los casos, el sentido denotativo. En un nivel inicial, por tanto, sería suficiente abordar la reformulación objetiva de cioè, explicando que, además, sirve para introducir reformulaciones de tipo subjetivo dentro de los valores metatextuales que puede desempeñar y que, además, aunque no lo hayamos tratado en este trabajo, puede realizar otras funciones como regular las relaciones entre los interlocutores en un acto comunicativo (dentro de valores metacomunicativos) o incluso funciones que requieren por parte del destinatario un esfuerzo de intelección para detectar las relaciones que se mantienen entre los distintos elementos del discurso o entre lo expresado y lo que realmente se quiere decir, que constituirían funciones cognitivas de distinto tipo.

\section{BIBLIOGRAFÍA}

Ambruzzi, L., Nuovo dizionario spagnolo-italiano, italiano-spagnolo, Torino, Paravia, (1949) 1973.

Bach Martorell, C., "Reformular ¿una operación argumentativa aséptica?”, Sendebar, 7, 1996, pp. 255-271.

Barbero Bernal, J. C.- Flores Acuña, E., "Marcadores discursivos en el español coloquial de hoy", en F. San Vicente (ed.), Lessicografia bilingue e traduzione. Metodi, strumenti, approcci attuali, Milano, Polimetrica, 2006, pp. 233-248.

Battaglia, S., Grande dizionario della lingua italiana, Torino, UTET, (vol. III: CERTDAG), 1964.

Battisti, C.- Alessio, G., Dizionario etimologico italiano, Firenze, G. Barberà Editore, (vol. II: CA-FA), 1975.

Bazzanella, C., "I segnali discorsivi”, en L. Renzi - G. Salvi, (eds.), Grande grammatica italiana di consultazione, vol. III, Tipi di frase, deissi, formazione delle parole, Bologna, Il Mulino, 1995, pp. 225-257.

Bazzanella, C., "Segnali discorsivi nel parlato e nello scritto", en M. Dardano - A. Pelo - A. Stefinlongo, Scritto e parlato. Metodi, testi e contesti, Roma, Aracne, 2001, pp. 79-97.

Bazzanella, C., "Segnali discorsivi e sviluppi conversazionali”, en F. Albano Leoni R. Giordano, Italiano parlato. Analisi di un dialogo, Napoli, Liguori editore, 2005, pp. 137-157.

Bazzanella, C.- Borreguero Zuloaga, M., "'Allora' y 'entonces': problemi teorici e dati empirici”, en E. Khachaturyan (ed.), Discourse markers in Romance languages, Oslo Studies in language 3 (1), 2011, pp. 7-45. 
Valores metatextuales de cioè en el marco de la gramática contrastiva it/es 273

Berretta, M., "Connettivi testuali in italiano e pianificazione del discorso", en L. Coveri (a cura di), Linguistica testuale. Atti del XV Congresso internazionale di Studi della SIL, Roma, Bulzoni, 1984, pp. 237-254.

Borreguero Zuloaga, M., "La traducción de los marcadores del discurso: valores, funciones, posiciones y otros problemas”, en D. Sáez et al.(eds.), Últimas tendencias en traducción e interpretación, Frankfurt, Iberoamericana Vervuert, 2011, 123-139.

Bortolini, U. - Tagliavini, C. - Zampolli, A., Lessico di frequenza della lingua italiana contemporanea, Milano, Garzanti, 1972.

Calvi, M. ${ }^{\text {a }}$., Didattica di lingue affini. Spagnolo e italiano, Milano, Guarini Scientifica, 1995.

Calvi, M. a V. - Mapelli, G., "Los marcadores bueno, pues, en fin, en los diccionarios español e italiano", Artifara, 4, (gennaio-giugno 2004), <http://www.cisi.unito.it/ artifara/rivista4/testi/marcadores.asp $>$ 5/11/2013

Calvo Rigual, C., "Italiano bene / va bene, be' / va be' e spagnolo bien, bueno. Analisi contrastiva nel parlato", Quaderns de Filologia, 6, 2001, pp. 53-80.

Calvo Rigual, C. - Giordano, A., Diccionario avanzado italiano-spagnolo, españolitaliano, Barcelona, Herder, 2011.

Carbonell, S., Dizionario fraseologico completo. Spagnolo-italiano e italiano-spagnolo, Milano, Hoepli, 1986.

Carrera Díaz, M., Curso de lengua italiana. Parte teórica, Barcelona, Ariel Lenguas Modernas, (1984) 1992.

Casado Velarde, M., "Los operadores discursivos es decir, esto es, o sea y a saber en español actual: valores de lengua y funciones textuales”, Lingüistica Española Actual, XIII, 1991, pp. 87-116.

Cortelazzo, M. - Zolli, P., Il Nuovo Etimologico. DELI Dizionario Etimologico della Lingua Italiana, Bologna, Zanichelli, 1999.

Dardano, M. - Trifone, P., Grammatica italiana con nozioni di linguistica, Bologna, Zanichelli Editore, 1989.

De Mauro, T., Guida all'uso delle parole, Roma, Editori Riuniti, 1980.

De Mauro, T., et al., Lessico di frequenza dell'italiano parlato, Milano, Etaslibri, 1993. En red: <http://badip.uni-graz.at> 2/07/2013

De Mauro, T., GRADIT Grande dizionario italiano dell'uso, Torino, UTET, (vol. II: CH-FL), 2000.

Devoto, G. - Oli, G. C., Il dizionario della lingua italiana, Firenze, Le Monnier, 1990.

Espasa Paravia, Il dizionario spagnolo-italiano, italiano-spagnolo, Milano, Paravia, 2005.

FERnÁndez Loya, C., "La traducción y el análisis contrastivo de los marcadores del discurso. Los casos de infatti y en efecto", 2004, <http://cvc.cervantes.es/literatura/ aispi/pdf/20/II_08.pdf> 4/12/2013

Ferrari, A. - Zampese, L., Dalla frase al testo. Una grammatica per l'italiano, Bologna, Zanichelli, 2000.

Ferrini, S., 'Cioè' nell'italiano contemporaneo, Perugia, LE Edizioni Università per Stranieri, 1985. 
Flores Acuña, E., "La traducción de los marcadores del discurso en italiano y español: el caso de insomma", TRANS. Revista de traductología, 7, 2003a, pp. 33-45, <http:// www.trans.uma.es/Trans_7/t7_33-45_EFlores.pdf> 25/12/2013

FLORES AcuÑa, E., Los marcadores de reformulación: análisis aplicado a la traducción español I italiano de en fin $y$ de hecho, Málaga, Servicio de Publicaciones de la Universidad, Tesis doctoral en red <www.contrastiva.it/baul_contrastivo/dati/barbero/Flores Acuña_tesisdoctoral.pdf $>$.

Flores Acuña, E., "Los marcadores de control de contacto en el español hablado contemporáneo: estudio contrastivo español e italiano", en F. San Vicente (ed.), Particulas / Particelle. Estudios de lingüística contrastiva español e italiano, Bologna, CLUEB, 2007, pp. 217-232.

Flores Acuña, E., "La reformulación del discurso en español en comparación con el italiano. Estudio contrastivo de los marcadores de reformulación”, en M. ${ }^{a}$ P. Garcés Gómez (ed.), 2009, pp. 93-136.

Flores Requejo,M.M. J.,Los marcadores del discurso en españolpeninsulary sus equivalencias en italiano, 1. Estructuradores de la información, conectores, reformuladores y operadores discursivos, Roma, Aracne Editrice, 2012a.

Flores Requejo, M.a J., Estudio de los marcadores bueno, bien $y$ vamos, $y$ de sus equivalencias en italiano. Los marcadores del discurso en español peninsular y sus equivalencias en italiano 2, L’Aquila, L'Una, 2012b.

Fogarasi, M., Grammatica italiana del Novecento, Roma, Bulzoni Editore, (1969) 1984.

Fuentes Rodríguez, C., "Conclusivos y reformulativos", Verba, 20, Santiago de Compostela, Universidade de Santiago de Compostela, 1993, pp. 171-198.

Gabrielli, A., Dizionario Linguistico Moderno, Verona, Edizioni Scolastiche Mondadori, (1956) 1969.

Gabrielli, A., Grande dizionario illustrato della lingua italiana, Milano, Mondadori, 1989.

Garcés Gómez, M. a P., La organización del discurso: marcadores de ordenación y de reformulación, Madrid-Frankfurt, Iberoamericana-Vervuert, 2008.

Garcés Gómez, M. a P., La reformulación del discurso en español en comparación con otras lenguas (catalán, francés, italiano, inglés, alemán e islandés), Madrid, Boletín Oficial del Estado, Vol. 58 de Colección Monografías, 2009.

Greenbaum, S., Studies in English Adverbial Usage, London, Longman, 1969.

Guil Povedano, P., "Marcadores discursivos de L1 en la interlengua de aprendices de italiano L2", ponencia en el Coloquio internacional Marcadores del discurso en las lenguas románicas: un enfoque contrastivo, Madrid, Universidad Complutense, 2010, en M. Borreguero Zuloaga - S. Gómez-Jordana Ferrari (eds.), Marqueurs du discours dans les langues romanes: une approche contrastive, Limoges, Lambert Lucas (en prensa).

Gülich, E. - Котsснi, T., "Les marqueurs de reformulation paraphrastique", Cabiers de Linguistique Française, 5, 1983, pp. 305-351.

Gülich, E. - Котsсhi, T., "Discours Production in Oral Communication. A Study Based on French", en U. Quasthoff (ed.), Aspects of Oral Communication, Berlin, De Gruyter, 1995, pp. 30-66.

Hossbach, S., Zu Redewiederaufnabme im Diskurs, Münster, Lit, 1997. 
Котsсні, T., "Formulierungspraxis als Mittel der Gesprächsaufrechterhaltung”, en K. Brinker et al. (eds.), Text-und Gesprächslinguistik, Berlin / New York, De Gruyter, vol. 2, 2001, pp. 1340-1348.

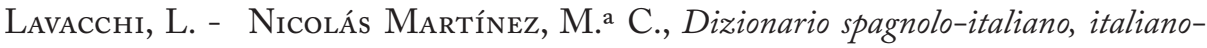
spagnolo, Firenze, Le Lettere, (2000) 2003.

Lenarduzzi, R., "El operador anche del italiano y sus formas equivalentes en español", Rivista della Facoltà di Lingue e Letterature straniere dell'Università di Venezia, XXXIV, 1-2, 1995, pp. 197-216.

López Serena, A. - Borreguero Zuloaga, M., "Los marcadores del discurso y la variación lengua hablada vs. lengua escrita”, en Ó. Loureda - E. Acín (coords.), 2010, pp. 325-405.

Lonzi, L., "Il sintagma avverbiale", en L. Renzi - G. Salvi (a cura di), Grande grammatica di consultazione, vol. II, Bologna, il Mulino, 1991, pp. 341-412.

Loureda Lamas, O. - Acín Villa, E. (coords.), Los estudios sobre marcadores del discurso en español, hoy, Madrid, Arco/Libros, 2010.

Mara, E., "Per un'analisi dei segnali discorsivi nell'italiano parlato", en K. Lichem et al. (eds.), Parallela 2. Aspetti della sintassi dell'italiano contemporaneo, Tübingen, Narr, 1986, pp. 177-189.

Martín Zorraquino, M. a A. - Montolío Durán, E. (coords.), Los marcadores del discurso. Teoría y análisis, Madrid, Arco/Libros, 1988.

Martín Zorraquino, M. a A., "Los marcadores del discurso y su morfología”, en Ó. Loureda - E. Acín (coords.), 2010, pp. 93-181.

Martín Zorraquino, M. a A. - Portolés Lázaro, J., "Los marcadores del discurso", en I. Bosque - V. Demonte (eds.), Gramática Descriptiva de la Lengua Española, vol. 3: Entre la oración y el discurso. Morfología, Madrid, Espasa, 1999, pp. 4051-4214.

Martínez Amador, E. M. a , Diccionario italiano-español, Barcelona, Sopena, 1965.

Montolío Durán, E., "La teoría de la relevancia y el estudio de los marcadores discursivos”, en Ma . A. Martín Zorraquino - E. Montolío Durán (coords.), 1988, pp. 93-119.

Muñoz Medrano, M.a C., "Uso contrastivo de los marcadores discursivos (españolitaliano) a partir del texto literario", Actas del XXIII Congreso AISPI, 2005, pp. 391407, <http://cvc.cervantes.es/literatura/aispi/pdf/22/II_24.pdf> 24/11/2013

Palazzi, F., Il Piccolo Palazzi, Milano, Fabbri, 1979.

Pittàno, G., Sinonimi e contrari. Dizionario fraseologico delle parole equivalenti, analoghe e contrarie, Bologna, Zanichelli, (1987) 2006.

RAE, Nueva gramática de la lengua española. Sintaxis II, Madrid, Espasa, 2009.

Rossari, C., "Projet pour une typologie des opérations de reformulation", Cabiers de linguistique française, 11, 1990, pp. 345-359.

Rossari, C., Les opérations de reformulation, Bern, Peter Lang, 1993.

Roulet, E., "Complétude interactive et connecteurs reformulatifs", Cabiers de linguistique française, 8, 1987, pp. 111-140.

Sabatini, F.- Coletti, V., Il Sabatini Coletti. Dizionario della Lingua italiana, 2011, <http://dizionari.corriere.it/dizionario_italiano/> 27/11/2013 
Sáinz González, M. ${ }^{a}$ E., Marcadores del discurso e interferencia. Estudio Contrastivo español / italiano, Venezia, Cartotecnica veneziana editrice, 2003.

SÁinz González, M. ${ }^{a}$ E., "También / anche: estudio semántico contrastivo”, en G. Bazzocchi - P. Capanaga, Mediación lingüistica de lenguas afines: español / italiano, Bologna, Gedit, 2006, pp. 23-45.

Sañé, S.- Schepisi, G., Il Dizionario di spagnolo. Dizionario spagnolo-italiano, italianospagnolo, Bologna, Vox Zanichelli, 2005.

Scorretti, M., "Le strutture coordinate", en L. Renzi (a cura di), Grande grammatica di consultazione, vol. I, Bologna, il Mulino, 1988, pp. 227-270.

Sensini, M., La grammatica della lingua italiana, Milano, Mondadori, 1997.

Serianni, L., Grammatica italiana. Italiano comune e lingua letteraria, Torino, UTET, 1988.

Solsona Martínez, C., "Funciones discursivas del marcador insomma en la enseñanza del italiano/L2 a hispanohablantes”, Cuadernos de Filología Italiana, 18, Universidad Complutense de Madrid, 2011, pp. 45-74.

Solsona Martínez, C., "Los marcadores discursivos en la pragmagramática del italiano/L2 para hispanohablantes: el caso de insomma", Zaragoza, Institución Fernando el Católico, en prensa.

VÁzquez PÉrez, J. A., "Mecanismos de atenuación en español e italiano: quizá y forse", redELE, 12, febrero 2008, en red: <http://www.educacion.es/redele/Revista12/ JoseAngelVazquez.pdf/> 27/11/2013

TAм, L., Dizionario spagnolo-italiano, italiano-spagnolo, Milano, Hoepli, 1998.

Treccani, Vocabolario on line. Enciclopedia Treccani, <www.treccani.it/vocabolario/cioè>

Zingarelli, N., Vocabolario della lingua italiana, Bologna, Zanichelli, 1995.

\section{Bibliografía de textos:}

(BT1): http://freeforumzone.leonardo.it/lofi/Domandina-/D7574655.html

(BT2): http://www.corriere.it/cultura/11_giugno_08/farkas-dizionario-assiro-

babilonese_9736da36-91cb-11e0-9b49-77b721022eeb.shtml

(BT3): http://natgeoadventure.tv/es/Post.aspx?Id=6160

(BT4): http://sports.groups.yahoo.com/group/FoggiaCalcio/message/3347

(BT5): http://www.pierpaolopasolini.eu/saggistica_sviluppo-progresso.htm

(BT6): http://palermo.repubblica.it/cronaca/2012/01/28/news/i_naufraghi_siciliani_ della_concordia_no_a_risarcimento_indecente-28900535/?ref=search

(BT7): http://www.infantiae.org/nidospazi2905.asp?st=1

(BT8): http://www.governo.it/GovernoInforma/dialogo/aree/agenda_digitale/agenda_ digitale_01.html

(BT9): T. Marin y S. Magnelli (2006): Nuovo Progetto italiano 1. Corso multimediale di lingua e civiltà italiana (A1-A2), Roma, Edilingua, p.170.

(BT10): http://it.answers.yahoo.com/question/index?qid=20121114134008AAtDIgd

(BT11): http://www.legnostorto.com/index. php?option=com_content\&task=view\&id=35139

(BT12): http://torino.notizie.it/sai-perche-paghi-la-benzina-1-80-euro-al-litro/ 
(BT13): http://www.formspring.me/r/che-paese-e-questo-

(BT14): http://www.corriere.it/salute/nutrizione/12_dicembre_12/anoressia-modelletaglie-forti-pubblicita_3b924154-3d49-11e2-80a1-638b05adae06.shtml

(BT15): http://www.formazionepsichiatrica.it/ultimo.html

(BT16): http://www.consilium.europa.eu/moresearchresultsregistry?search=cio\%C3\% A8\&lang=it

(BT17): http://it.answers.yahoo.com/question/index?qid=20120611051912AAPsyrM

(BT18): http://www.lastampa.it/2012/12/14/economia/germania-la-piu-grandeondata-migratoria-degli-ultimi-cinquant-anni-rylI3RtQVSpnD5XHKa1R4J/ pagina.html

(BT19): http://it.answers.yahoo.com/question/index?qid=20121130070451AArPv9i

(BT20): entrevista del periodista Bernardo Iovene a Letizia Moratti, programa 'Report' de la RAI www.report.rai.it/ con fecha 19/11/2006.

(BT21): http://www.lastampa.it/2012/12/14/economia/germania-la-piu-grandeondata-migratoria-degli-ultimi-cinquant-anni-rylI3RtQVSpnD5XHKa1R4J/ pagina.html

(BT22): entrevista del periodista Bernardo Iovene a Letizia Moratti, programa 'Report' de la RAI www.report.rai.it/ con fecha 19/11/2006.

(BT23): http://www.vincenzoalvino.it/gravidanza-infezioni-malattie-infettive.php

(BT24): http://www.cosmopolitan.it/beauty/Viso-S.O.S.-antistanchezza/(offset)/3\#04

(BT25): M. La Grassa (2011): L'italiano all'Università, Roma, Edilingua, p.116.

(BT26): http://www.acquese.it/index.php/notizie/news-dellacquese/ item/4299-movimento-5-stelle-di-acqui-terme?tmpl=component\&print=1

(BT27): http://www.ilgiornale.it/news/conto-rovescia-coppie-fatto-anno-registro. html

(BT28): http://www.vesparesources.com/off-topics/32247-come-funziona-cioe-dovesi-attacca.html

(BT29): http://ricerca.repubblica.it/repubblica/archivio/repubblica/2011/04/04/javierpastore-detto-el-flaco-cioe-il.html?ref=search

(BT30): http://archivio.antimafiaduemila.com/rassegna-stampa/46-marco-travaglio/20706-la-diretta-con-passaparola.html?start=3

(BT31): película Un sacco bello, 1980, dirigida por Carlo Verdone

(BT32): http://ricerca.repubblica.it/repubblica/archivio/repubblica/2011/07/15/

licenziate-sottopagate-cioe-donne.html? ref=search

(BT33): http://en.bab.la/dictionary/italian-english/solo-una-cosa

(BT34): http://faculty-web.at.northwestern.edu/music/gjerdingen/partimenti/ collections/Furno/regoleP5.htm

(BT35): http://notizie.tiscali.it/regioni/abruzzo/socialnews/Beha/2153/articoli/Laltro-discorso-di-Berlusconi-Il-premier-uscente-cio-uscito-prepar-un-congedodiverso-pi-incisivo-e-veritiero.html/

(BT36): http://forum.playitusa.com/viewtopic.php?f=12\&t=15453\&start=4350

(BT37): http://antoniodini.blogspot.com.es/2004_09_01_archive.html

(BT38): http://nuvolerosa-serena.blogspot.com.es/2008/07/di-bere-non-ho-voglia. html 
(BT39): http://forum.alfemminile.com/forum/matern1/_f320353_matern1Opinioni-su-ecografia-3d.html

(BT40): http://es.answers.yahoo.com/question/index?qid=20120427080244AAFUtIa

(BT41): http://www.icroccafluvione.it/LABORATORIO_ITALIANO/ GIORNALINO/MSG.htm

(BT42): http://www.bonjovi.it/forum/viewtopic.php?id=8281

(BT43): Stefano Congia, 18 Rotoli, 2006, Cagliari, Davide Zedda Editore, p.54

(BT44): entrevista del periodista Bernardo Iovene a Letizia Moratti, programa 'Report' de la RAI www.report.rai.it/ con fecha 17/05/2009.

(BT45): http://espresso.repubblica.it/dettaglio/monti-cioe-sobrio/2168850

(BT46): http://www.glialtrionline.it/2012/09/28/

monti-chiede-il-bis-ma-non-si-candida-a-questo-punto-aboliamo-le-elezioni/

(BT47): http://www.clonline.org/articoli/ita/vol_Papa1211_intern.htm

(BT48): entrevista del periodista Bernardo Iovene a Letizia Moratti, programa 'Report' de la RAI www.report.rai.it/ con fecha 19/11/2006.

(BT49): http://www.ciao.it/Whirlpool_Opinione_338503

(BT50): http://www.ilcambiamento.it/vegetarianesimo_veganesimo/dieta_futuro_ vegetariana.html

(BT51): http://politicainrete.it/forum/movimenti-e-cultura-politica/padania/12230pirati-mare-nel-corno-dafrica-no-cioe-si-napoli.html

(BT52): www.gazzetta.it/Calcio/Primo_Piano/.../VOL.2\%20PAIRETTO.doc 